\title{
Facial Nerve Arterial Arcade Supply in Dural Arteriovenous Fistulas: Anatomy and Treatment Strategies
}

\author{
(D) K.D. Bhatia, (D) H. Kortman, (D) H. Lee, (D)T. Waelchli, (DI. Radovanovic, (D).D. Schaafsma, (D) V.M. Pereira, and (D)T. Krings
}

\begin{abstract}
BACKGROUND AND PURPOSE: Endovascular treatment of petrous dural AVFs may carry a risk of iatrogenic facial nerve palsy if the facial nerve arterial arcade, an anastomotic arterial arch that supplies the geniculate ganglion, is not respected or recognized. Our purpose was to demonstrate that the use of a treatment strategy algorithm incorporating detailed angiographic anatomic assessment allows identification of the facial nerve arterial arcade and therefore safe endovascular treatment.
\end{abstract}

MATERIALS AND METHODS: This was a retrospective cohort study of consecutive petrous dural AVF cases managed at Toronto Western Hospital between 2006 and 2018. Our standard of care consists of detailed angiographic assessment followed by multidisciplinary discussion on management. Arterial supply, primary and secondary treatments undertaken, angiographic outcomes, and clinical outcomes were assessed by 2 independent fellowship-trained interventional neuroradiologists.

RESULTS: Fifteen patients had 15 fistulas localized over the petrous temporal bone. Fistulas in all 15 patients had direct cortical venous drainage and received at least partial supply from the facial nerve arterial arcade. Following multidisciplinary evaluation, treatment was performed by endovascular embolization in 8 patients (53\%) and microsurgical disconnection in 7 patients (47\%). All patients had long-term angiographic cure, and none developed iatrogenic facial nerve palsy.

CONCLUSIONS: By means of our treatment strategy based on detailed angiographic assessment and multidisciplinary discussion, approximately half of our patients with petrous AVFs were cured by endovascular treatment, half were cured by an operation, and all had preserved facial nerve function.

ABBREVIATIONS: $\mathrm{EVOH}=$ ethylene-vinyl alcohol copolymer; MMA = middle meningeal artery; TAE transarterial embolization; TVE $=$ transvenous embolization

$\mathbf{T}$ he arterial arcade of the facial nerve is an anastomotic arch of arteries traversing the petrous temporal bone that supplies the geniculate ganglion and tympanic segment of the facial nerve. ${ }^{1,2}$ Care must be taken during embolization from the proximal aspect of external carotid artery branches to avoid occlusion of the facial nerve arterial arcade, which may result in iatrogenic facial nerve (Bell) palsy. ${ }^{3,4}$ The risk of occluding the facial nerve arterial arcade is particularly elevated when embolizing petrous

Received October 26, 2019; accepted after revision January 14, 2020. From the Division of Neuroradiology (K.D.B., H.K., H.L., V.M.P., T.K.), Joint Department of Medical Imaging; Division of Neurosurgery (T.W., I.R., V.M.P., T.K.), Department of Surgery; and Division of Neurology (J.D.S.), Department of Medicine, Toronto Western Hospital, Toronto, Ontario, Canada.

Please address correspondence to Kartik Dev Bhatia, MD, Division of Neuroradiology, Level 3, Toronto Western Hospital, 399 Bathurst St, Toronto, M5T 2S8, ON, Canada; e-mail: Kartik.bhatia@uhn.ca

Indicates article with supplemental on-line tables. Indicates article with supplemental on-line photo. http://dx.doi.org/10.3174/ajnr.A6449 dural AVFs because these lesions are frequently supplied by the vessels that form the arterial arcade. ${ }^{1,3,5,6}$

\section{Anatomy}

Two arteries form the facial nerve arterial arcade: 1) the petrous branch of the middle meningeal artery (MMA), and 2) the stylomastoid branch of the posterior auricular or occipital artery (Fig 1). ${ }^{1,3,7}$ Branches of these 2 arteries anastomose adjacent to the geniculate ganglion. ${ }^{2,3}$ The arcade can be reinforced by the inferior tympanic artery, a branch of the ascending pharyngeal artery that travels to the tympanic cavity alongside the Jacobson nerve.,

The petrous branch of the MMA usually arises within the first $10 \mathrm{~mm}$ distal to the entry of the MMA to the middle cranial fossa via the foramen spinosum but can arise just proximal to the foramen. ${ }^{5,8-10}$ It then extends posterolaterally toward the hiatus of the facial nerve canal where it gives off small branches to supply the greater petrosal nerve, which travels in the canal. ${ }^{8,10}$ The artery travels within the canal (25\%) or external to it (75\%), piercing the petrous bone more laterally before supplying the geniculate 

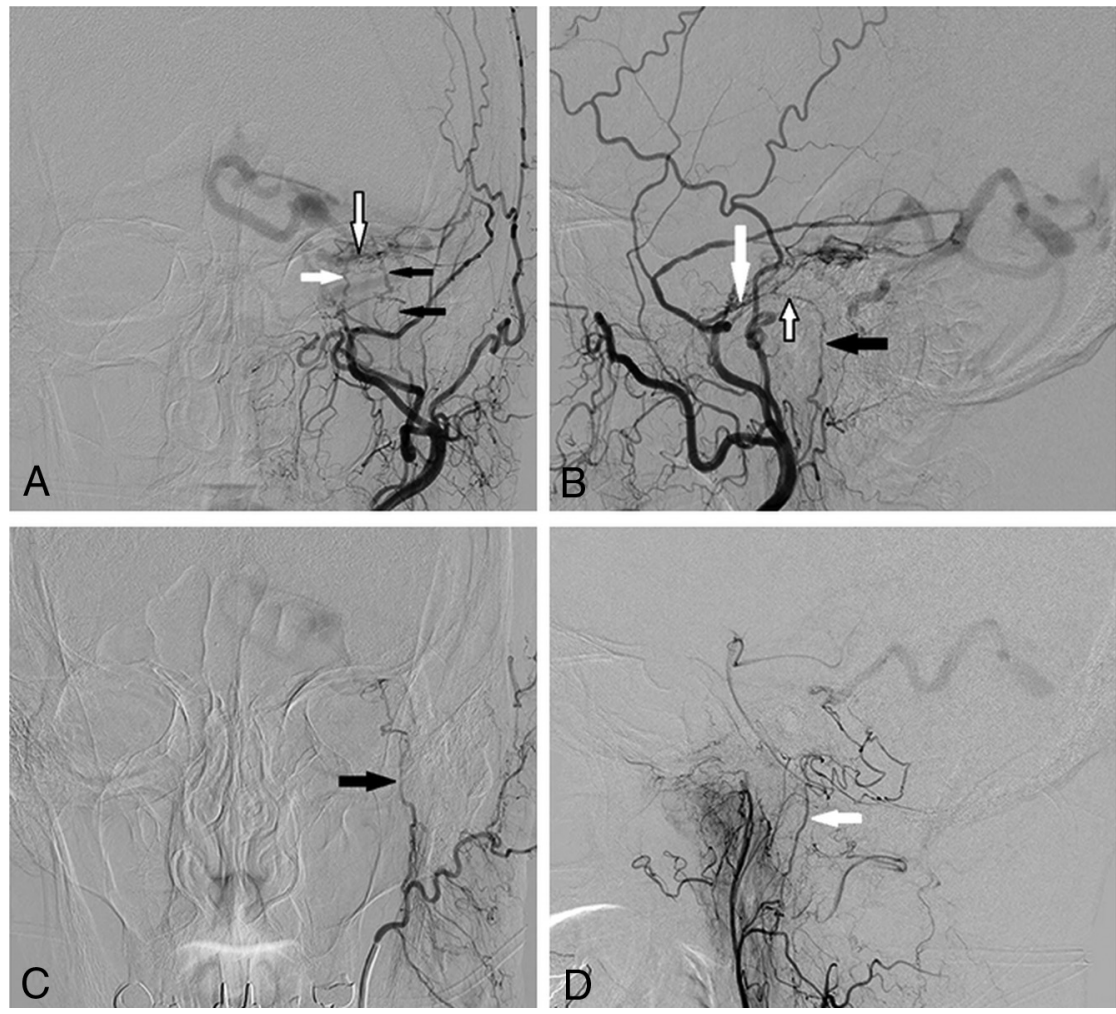

FIG 1. DSA images via left external carotid artery injection from a patient with a left petrous AVF (patient 5) demonstrate the anatomy of the facial nerve arterial arcade. A, Anterior-posterior projection demonstrates supply to the fistula by the petrous branch of the left MMA (white arrow), stylomastoid branch of the left posterior auricular artery (black arrows), and the anastomotic arcade between these 2 arteries (black-border arrow). B, Lateral projection shows the petrous branch of the MMA (white arrow), stylomastoid artery (black arrow), and the anastomotic facial nerve arterial arcade (black-border arrow). C, Anterior-posterior projection during selective injection of the left posterior auricular artery confirms supply to the fistula from the left stylomastoid artery (black arrow). D, Lateral projection during selective left ascending pharyngeal artery injection demonstrates additional supply to the AVF from its hypoglossal branch (white arrow).

ganglion by 1-3 small branches and then supplying the second (tympanic) segment of the intraosseous facial nerve. ${ }^{3,8,10}$

The stylomastoid artery can arise from the posterior auricular artery, from the proximal third of the occipital artery, or from a common trunk of these 2 arteries. ${ }^{1,3}$ Traveling superiorly through the stylomastoid foramen and lying anterior or anteromedial to the facial nerve, it provides arterial supply to the third (mastoid) intraosseous segment of the facial nerve. ${ }^{7,8,11}$ The artery then ascends to the level of the facial genu and the tympanic cavity where it divides into several branches and provides additional supply to the second (tympanic) segment of the nerve. ${ }^{7,8}$ Here, a network of its branches anastomoses with branches of the petrous branch of the MMA to form the facial nerve arterial arcade (Fig 1). ${ }^{7}$ These arteries are, in the absence of shunts, most often too small to be detected on conventional angiography. ${ }^{2}$

\section{Rationale for the Study}

Petrous dural AVFs drain into cortical veins (most often the superior petrosal vein, ie, vein of Dandy) rather than directly into dural venous sinuses. ${ }^{6}$ They are therefore highgrade fistulas (Borden III, Cognard III-IV) ${ }^{12,13}$ and thus warrant treatment due to their well described risk of subsequent neurologic deterioration or rupture. ${ }^{6,14}$ At our institution, we use management principles based on detailed angiographic anatomic assessment and multidisciplinary discussion (retrospectively summarized in our treatment algorithm shown in Fig 2) to avoid iatrogenic facial nerve palsy while achieving angiographic cure. In this study, we assess the treatment approaches and outcomes using these principles.

\section{MATERIALS AND METHODS}

Ethics approval for this study was granted by the Research Ethics Board of the University Health Network, Toronto (approval No. 19-5018).

\section{Study Design and Selection Criteria}

This was a retrospective study of a cohort of patients with intracranial AVFs managed at Toronto Western Hospital between 2006 and 2018. Inclusion criteria were the following: 1) confirmed diagnosis of intracranial AVF on DSA with the fistula point localized over the petrous temporal bone, and 2) follow-up DSA or time-resolved MRA after an interventional or conservative management. All included cases underwent data collection and imaging analysis.

\section{Data Collection and Analysis}

In all cases, 6-vessel cerebral angiography, high-frame-rate magnified acquisitions, and 3D rotational angiography with MPRs were undertaken for treatment planning. Clinical data points were obtained from the electronic patient records. Baseline and followup DSA and MRA for each patient were independently reviewed by 2 fellowship-trained interventional neuroradiologists (K.D.B. and H.K.). Disagreements were resolved by consensus; otherwise, they were resolved by the supervising senior interventional neuroradiologist (T.K.). We assessed the following imaging characteristics of each petrous AVF: location, arterial supply (in particular supply by vessels that form the facial nerve arterial arcade), venous drainage, Borden ${ }^{12}$ and Cognard ${ }^{13}$ classifications, endovascular approach, embolic agents used, angiographic outcome after primary treatment, and long-term angiographic outcome.

\section{Treatment Planning}

All AVF cases were discussed in a multidisciplinary conference among neurologists, radiosurgeons, cerebrovascular neurosurgeons, and interventional neuroradiologists to decide on management. On the basis of our review of the conference minutes for these cases, the 


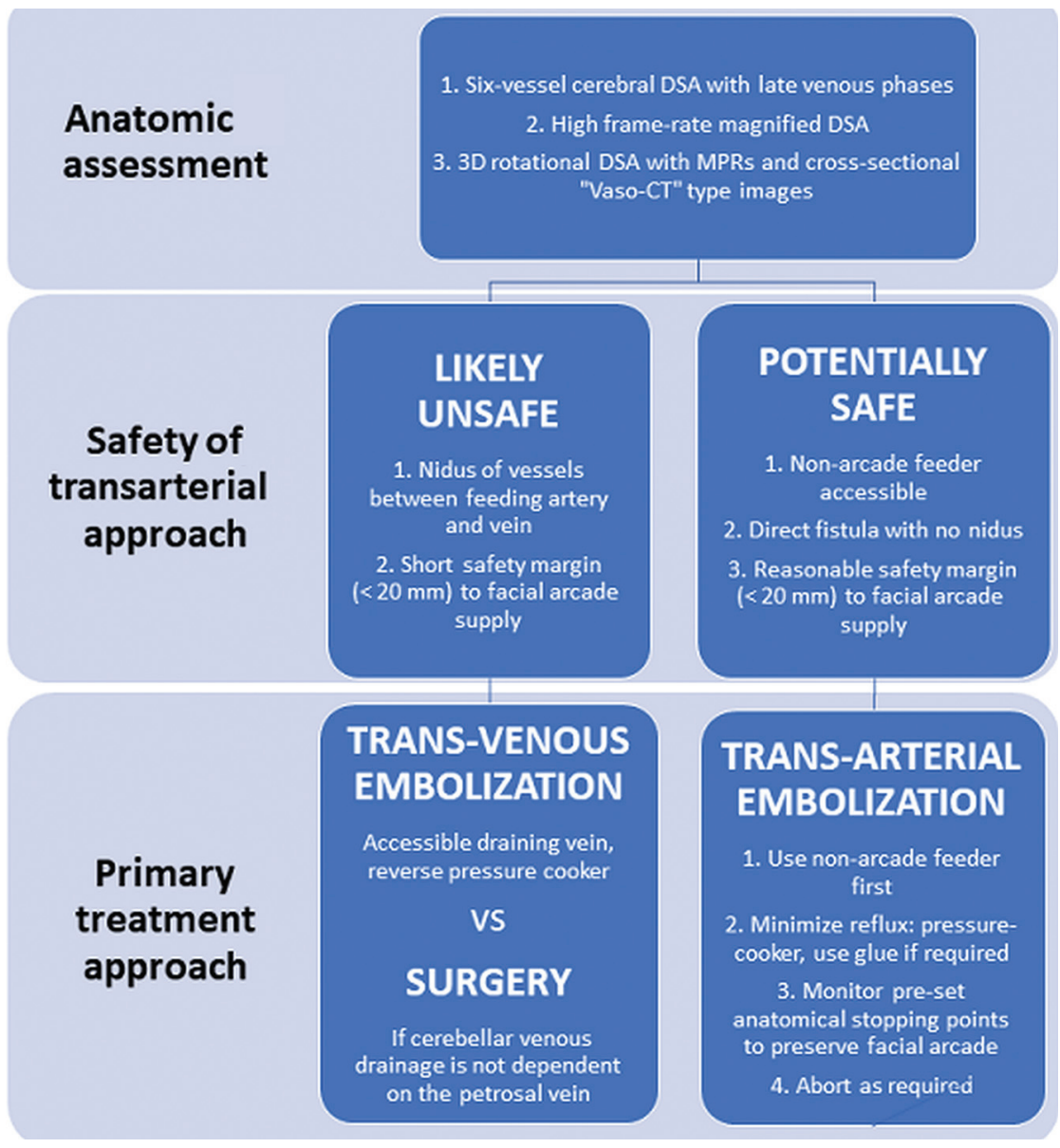

FIG 2. Retrospective summary of our treatment strategy algorithm for petrous dural AVFs. available in a dimethyl-sulfoxidecompatible microcatheter (15 mm tip, Apollo Onyx Delivery Microcatheter; Medtronic, Irvine, California)

In the absence of favorable features for TAE, transvenous embolization (TVE) would be considered if there was an accessible draining vein that could be safely occluded. In the remaining cases or if endovascular treatment was unsuccessful, microsurgical disconnection was recommended.

\section{RESULTS}

Fifteen patients ( 5 women; mean age, 63.5 years) had 15 dural AVFs with the fistulous point localized over the petrous temporal bone $(8.7 \%$ of all patients with dural arteriovenous fistulas managed at our center). Clinical presentations are detailed in On-line Table 1. All 15 petrous shunts had direct cortical venous drainage (Borden type III), ${ }^{1} 6$ were Cognard type III (cortical venous drainage), and 9 were Cognard type IV (ie, with cortical venous ectasia). ${ }^{13}$ Angiographic characteristics are detailed in On-line Table 2.

\section{Arterial Supply and Venous Drainage}

All 15 patients (100\%) demonstrated primary treatment choice was determined by taking a stepwise approach. First, consensus agreement was reached that conservative treatment was not indicated in these cases due to the direct cortical venous drainage that occurs in petrous AVFs. Second, anatomic factors were assessed that would allow a safe endovascular treatment through an arterial, venous, or combined approach. For this article, we have retrospectively summarized the management principles outlined in the conference minutes for these cases in a treatment algorithm, shown in Fig 2.

Factors favoring an attempt at primary transarterial embolization (TAE) included the following: 1) accessible nonarcade arterial feeders supplying the AVF, 2) a direct arteriovenous fistulous point without an intervening nidus, and 3) a reasonable safety margin (for our purposes defined as the ability to place the distal end of the embolization microcatheter a minimum of $20 \mathrm{~mm}$ distal to the origin of or communication points with vessels of the facial nerve arterial arcade) for reflux of the embolic agent while preserving facial nerve arterial supply. The choice of a minimum distance of $20 \mathrm{~mm}$ was based on our experience of the working margin required to safely withdraw the microcatheter once glue begins to reflux and, for pressure-cooker/ethylene-vinyl alcohol copolymer $(\mathrm{EVOH})$ approaches, the minimum detachable tip length arterial supply to the AVF from either or both vessels involved in the facial nerve arterial arcade. The petrous branch of the MMA was seen in 13 patients (87\%), while the stylomastoid artery was seen in 9 cases (60\%); both vessels were involved in 7 cases (47\%). Additional nonarcade supply to the fistulas discussed herein is outlined in On-line Table 2. The venous drainage outflow pathways were through cortical veins in all cases (superior petrosal vein, $n=13$; subtemporal vein, $n=2$ ). The detailed drainage patterns are summarized in On-line Table 3.

\section{Primary Treatment Choice}

Using the treatment strategy algorithm outlined in Fig 2, the multidisciplinary conference opinion for the primary treatment approach was TAE in 8 cases, TVE in 3 cases, and an operation in 4 cases. One patient initially declined an operation and chose the alternative option of gamma knife radiosurgery but subsequently underwent microsurgical disconnection because of residual AVF filling 2 years later.

\section{Treatment Outcomes}

The primary and secondary treatments undertaken, curative treatment, complications, and long-term angiographic and functional outcomes are summarized in On-line Table 4. 


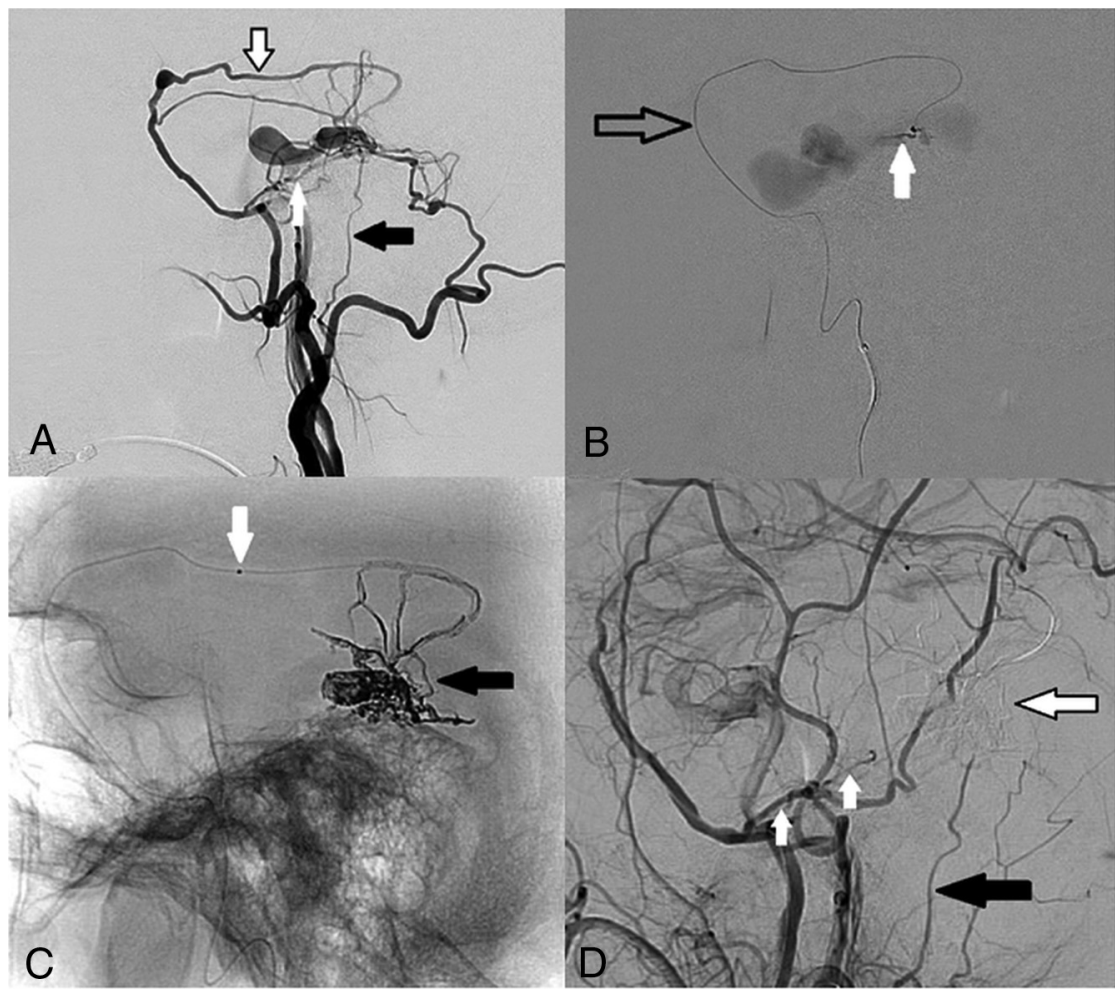

FIG 3. DSA and transarterial embolization using EVOH copolymer of a right-sided Borden III/ Cognard IV petrous dural AVF. All images are in the lateral projection. A, Right external carotid artery injection demonstrates arterial supply to the AVF from the squamous temporal branch of the right MMA (black-border arrow) from an enlarged petrous branch of the MMA (white arrow) and from an enlarged stylomastoid artery (black arrow). Note that the facial nerve arterial arcade is formed by the latter 2 vessels. B, A microcatheter is present in the squamous branch of the MMA (black-border arrow). Microcatheter injection DSA from a distal point in the vessel demonstrates the fistulous point (white arrow) entering an ectatic petrosal varix. C, Spot film following $\mathrm{EVOH}$ embolization via the squamous branch of the MMA demonstrates the $\mathrm{EVOH}$ cast (black arrow) across the fistulous point and into the venous sac. The proximal marker of the detachable tip is visible (white arrow). D, Magnified right common carotid artery injection following embolization demonstrates the subtracted EVOH cast (black-border arrow) with no remnant filling of the AVF. The petrous branch of the MMA (white arrows) and the stylomastoid artery (black arrow) remain patent after treatment. The patient had preserved facial nerve function postprocedure.

Of the 8 patients with primary TAE, 5 had angiographic cure after a single session. All 5 of these patients were treated using liquid embolic agents (glue $4, \mathrm{EVOH} 1$ ) to occlude the fistulous point, with the microcatheter placed distally in the squamous (nonpetrous) branch of the middle meningeal artery in all cases and additional glue embolization via the meningohypophyseal trunk in 1 case. An example of TAE (patient 3) using EVOH via the squamous branch of the MMA is demonstrated in Fig 3.

One case with TAE with angiographic cure (patient 1) was complicated by pial arterial infarction due to the passage of glue droplets across an external carotid-internal carotid anastomosis, in this case most likely between the squamous branch of the middle meningeal artery and the lateral tentorial branch of the meningohypophyseal trunk. The TAE session was aborted in 2 cases due to inability to gain a distal or safe microcatheter position (patients 2 and 13), and in a third case (patient 5), only partial fistula reduction was achieved; these cases underwent curative surgical treatment. All 3 cases of primary TVE (patients 7, 14, and 15) were cured using a reverse pressure-cooker technique (On-line Figure).

Microsurgical disconnection was recommended as the primary treatment in 4 cases in which an endovascular approach was deemed too dangerous (Fig 2) and as the secondary treatment in 3 unsuccessful TAE cases (see above). In all 7 cases, an extended retrosigmoid approach was used to expose and occlude the draining petrosal vein with subsequent angiographic cure. One primary surgical case (patient 6) was complicated by hemorrhagic venous infarction of the ipsilateral cerebellum.

In summary, all 15 patients had long-term angiographic cure, and none developed iatrogenic facial nerve palsy. Approximately half of these patients $(n=8)$ had cure by endovascular treatment, and half ( $n=7)$, by microsurgical disconnection. Two patients (patient 1 : TAE and patient 6: an operation) had significant treatment-related neurologic complications resulting in permanent worsening of their mRS at presentation by 1 point.

\section{DISCUSSION}

Endovascular treatment of petrous AVFs supplied by vessels of the facial nerve arterial arcade is associated with certain strategic and technical challenges to preserve facial nerve function. In our cohort, all patients with petrous AVFs had at least partial arterial supply to the fistula from vessels of the facial nerve arterial arcade. In addition, these patients warranted interventional treatment due to direct cortical venous drainage in all cases, in keeping with the known venous drainage pattern of lateral epidural shunts into cortical veins. ${ }^{15}$ Because of these challenges, some groups have adopted a primary surgical approach for petrous AVFs. ${ }^{14,16,17}$ Use of the principles outlined retrospectively in our treatment strategy algorithm (Fig 2) resulted in endovascular cure in approximately half of cases (8/15: 53\%) and surgical cure in the other half (7/15: 47\%), with preserved facial nerve function in all cases.

\section{Surgical Treatment}

Surgical management of AVFs is based on the principle that microsurgical disconnection of the draining vein will cure the AVF. ${ }^{18}$ Lawton et $\mathrm{al}^{17}$ recommended use of an extended retrosigmoid approach for petrosal AVFs to expose and occlude the superior petrosal (Dandy) vein as it enters the superior petrosal sinus. This involves lateral positioning for a vertical trajectory to 
the cerebellopontine angle and anterior mobilization of the skeletonized sigmoid sinus, allowing ideal visualization of the petrous-tentorial angle. ${ }^{14,17,18}$ In the series of Lawton et al of 8 patients with petrosal AVFs, all patients underwent presurgical TAE to minimize blood loss. ${ }^{17}$ Therefore, when safe to do so, an attempt at endovascular treatment is still the recommended primary approach. ${ }^{6,18}$

The surgical goal of disconnecting the superior petrosal vein carries a risk of cerebellar venous infarction if the ipsilateral cerebellum is dependent on the petrosal vein complex for drainage. ${ }^{19}$ This complication is well-described following petrosal vein sacrifice during microvascular decompression for trigeminal neuralgia (4\%-7\% in larger series). ${ }^{19,20}$ The rate of neurologic deterioration following an operation for petrosal AVFs may be even higher (13\%-33\% in small series, including facial nerve palsy, hemiparesis from venous infarct, and death from intraoperative cerebellar edema). ${ }^{17,21}$ Surgical management of petrosal AVFs, therefore, requires careful assessment of the cerebellar venous drainage pattern on DSA to ensure that the petrosal vein can be safely sacrificed.

\section{Transarterial Embolization}

The treatment goal for curative TAE is occlusion of the fistulous point and the foot of the draining vein. ${ }^{22}$ A safe TAE approach to petrosal AVFs is optimized by detailed analysis of high-framerate magnified angiography and $3 \mathrm{D}$ rotational angiography with MPRs. ${ }^{23,24}$ Anatomic factors that best allow safe TAE are outlined in the Materials and Methods section and in Fig 2. ${ }^{25,26}$ If such favorable factors are not present, then TVE may be considered. ${ }^{27}$ Otherwise, a primary surgical disconnection is suggested by our group (Fig 2).

The advantage of glue in petrosal AVFs is the ability to rapidly penetrate the fistulous point while minimizing reflux toward the facial arcade if a distal wedged position can be achieved. ${ }^{25}$ However, if a distal perifistulous microcatheter position cannot be achieved or the microcatheter is not retrieved at the appropriate moment of the injection, there may be glue inflow or reflux into the facial nerve arterial arcade. Other complications may involve gluing of the microcatheter tip so that it cannot be retrieved or nontarget embolization of pial arteries across external carotid-internal carotid anastomoses (ie, branches of the inferolateral or meningohypophyseal trunks), resulting in arterial infarction (as occurred in patient 1 in our series). ${ }^{1,28}$ Thus, the use of liquid embolic agents requires extensive experience with the agent, a distal microcatheter position, and a thorough knowledge of the external carotid-internal carotid anastomoses and cranial nerve supply in this region. ${ }^{1,25,28}$

$\mathrm{EVOH}$ can be injected more slowly without the need for rapid removal of the microcatheter (Fig 3), but it is associated with longer radiation times and risks of reflux into both external carotidinternal carotid anastomoses and cranial nerve supply. ${ }^{29,30}$ EVOH was used for TAE in 1 patient in our series (patient 3, Fig 3) with injection performed via the squamous branch of the MMA through a detachable-tip microcatheter. The use of detachable-tip microcatheters, which can also be combined with a pressure-cooker technique, in which a coil/glue plug is deployed over the detachable tip by a second microcatheter to minimize $\mathrm{EVOH}$ reflux, allows controlled embolization if there is a reasonable anatomic safety margin back to the facial arcade (the shortest available detachable-tip length is $15 \mathrm{~mm}){ }^{31}$ The presence of an intervening nidus between the embolization point and the venous drainage increases the potential for reflux of the embolic agent across nidal channels into the facial nerve arterial arcade (Fig 2 and On-line Figure).

\section{Transvenous Embolization}

TVE of petrosal AVFs may be considered when there are relative anatomic contraindications to TAE or TAE has failed to occlude the fistula. ${ }^{27}$ Safe TVE requires successful navigation of the microcatheter to the foot of the draining vein, limited tortuosity of the draining vein, and absence of normal cortical venous drainage into the target vein (Fig 2 and On-line Figure). ${ }^{32}$ To achieve retrograde flow of the embolic agent toward the fistula point, a reverse pressure-cooker (dual microcatheter) technique (On-line Figure) or a dual-lumen balloon may be required. ${ }^{32-34}$ Given the need for navigation in pial veins, this approach requires experience to prevent potentially catastrophic venous hemorrhagic complications and, thus, in the authors' opinion, should be performed only in centers with experience in pial transvenous approaches.

\section{Utility of Our Treatment Strategy Algorithm}

Our retrospective treatment-strategy algorithm (Fig 2) is based on detailed angiographic assessment and multidisciplinary discussion, with the aim of primary TAE or TVE when safe to do so. Safe microsurgical disconnection requires careful evaluation of the venous drainage of the cerebellum on preoperative DSA to ensure nondependence on the petrosal vein complex. Advancements in detachable-tip microcatheters, liquid embolics, and treatment strategies (eg, pressure-cooker technique) potentially allow greater rates of endovascular cure. ${ }^{17,35}$

\section{Limitations}

This study is limited by its retrospective nature and relatively small sample size.

\section{CONCLUSIONS}

Petrous AVFs are always supplied by arteries of the facial nerve arterial arcade and always have cortical venous drainage. This raises the risk of iatrogenic facial nerve palsy via endovascular arterial routes during clinically necessary treatments. Using the principles outlined in our treatment-strategy algorithm, approximately half of our patients were cured by endovascular treatment, half were cured by an operation, and all had preserved facial nerve function.

Disclosures: Kartik D. Bhatia-UNRELATED: Employment: University Health Network, Toronto, Comments: paid employment as clinical fellow in interventional neuroradiology at the University Health Network, Toronto. Timo KringsUNRELATED: Consultancy: Stryker, Medtronic, Penumbra; Royalties: Thieme; Stock/Stock Options: Marblehead.

\section{REFERENCES}

1. Geibprasert S, Pongpech S, Armstrong D, et al. Dangerous extracranial-intracranial anastomoses and supply to the cranial nerves: 
vessels the neurointerventionalist needs to know. AJNR Am J Neuroradiol 2009;30:1459-68 CrossRef Medline

2. Ozanne A, Pereira V, Krings T, et al. Arterial vascularization of the cranial nerves. Neuroimaging Clin N Am 2008;18:431-39 CrossRef Medline

3. Lapresle J, Lasjaunias P. Cranial nerve ischaemic arterial syndromes: a review. Brain 1986;109:207-16 CrossRef Medline

4. Lasjaunias P, Doyon D, Edouard A. Post-embolisation lower motor neurone facial paralysis: report of one case, discussion, prevention (author's transl.) [in French]. Ann Otolaryngol Chir Cervicofac 1978;95:595-602 Medline

5. Merland JJ, Moret J, Lasjaunias $P$, et al. Cranial osseous and meningeal blood supply (author's transl) [in French]. J Neuroradiol 1977;4:335-36 Medline

6. Li J, Ren J, Du S, et al. Dural arteriovenous fistulas at the petrous apex. World Neurosurg 2018;119:e968-76 CrossRef Medline

7. Minatogawa T, Kumoi T, Hosomi H, et al. The blood supply of the facial nerve in the human temporal bone. Auris Nasus Larynx 1980;7:7-18 CrossRef Medline

8. Dozõić A, Cetković M, Marinković S, et al. Vascularisation of the geniculate ganglion. Folia Morphol (Warsz) 2014;73:414-21 CrossRef Medline

9. Natali AL, Leo JT. Neuroanatomy, Middle Meningeal Arteries. StatPearls [Internet]. October 2018. https://www.ncbi.nlm.nih.gov/ books/NBK519545/. Accessed September 14, 2019

10. El-Khouly H, Fernandez-Miranda J, Rhoton AL Jr. Blood supply of the facial nerve in the middle fossa: the petrosal artery. Neurosurgery 2008;62(5 Suppl 2):ONS297-303; discussion ONS303294 CrossRef Medline

11. Upile T, Jerjes W, Nouraei SA, et al. The stylomastoid artery as an anatomical landmark to the facial nerve during parotid surgery: a clinico-anatomic study. World J Surg Oncol 2009;7:71 CrossRef Medline

12. Borden JA, Wu JK, Shucart WA. A proposed classification for spinal and cranial dural arteriovenous fistulous malformations and implications for treatment. J Neurosurg 1995;82:166-79 CrossRef Medline

13. Cognard C, Gobin YP, Pierot L, et al. Cerebral dural arteriovenous fistulas: clinical and angiographic correlation with a revised classification of venous drainage. Radiology 1995;194:671-80 CrossRef Medline

14. Westermaier T, Bendszus M, Solymosi L, et al. Surgical treatment of dural arteriovenous fistulas of the petrous apex. World Neurosurg 2012;77:e597-613 CrossRef Medline

15. Geibprasert S, Pereira V, Krings T, et al. Dural arteriovenous shunts: a new classification of craniospinal epidural venous anatomical bases and clinical correlations. Stroke 2008;39:2783-94 CrossRef Medline

16. Youssef PP, Schuette AJ, Cawley CM, et al. Advances in surgical approaches to dural fistulas. Neurosurgery 2014;74(Suppl 1):S32-41 CrossRef Medline

17. Lawton MT, Sanchez-Mejia RO, Pham D, et al. Tentorial dural arteriovenous fistulae: operative strategies and microsurgical results for six types. Neurosurgery 2008;62:110-124; discussion 124-15 CrossRef Medline

18. Radovanovic I, Wallace M. Cranial dural arterovenous fistula disconnection. In: Jandial R, McCormick P, Black P, eds. Core Techniques in Operative Neurosurgery. Philadelphia: Elsevier; 2019

19. Narayan V, Savardekar AR, Patra DP, et al. Safety profile of superior petrosal vein (the vein of Dandy) sacrifice in neurosurgical procedures: a systematic review. Neurosurg Focus 2018;45:E3 CrossRef Medline

20. Liebelt BD, Barber SM, Desai VR, et al. Superior petrosal vein sacrifice during microvascular decompression: perioperative complication rates and comparison with venous preservation. World Neurosurg 2017;104:788-94 CrossRef Medline

21. Gross BA, Du R. Surgical treatment of high grade dural arteriovenous fistulae. J Clin Neurosci 2013;20:1527-32 CrossRef Medline

22. Gross BA, Albuquerque FC, Moon K, et al. Evolution of treatment and a detailed analysis of occlusion, recurrence, and clinical outcomes in an endovascular library of $\mathbf{2 6 0}$ dural arteriovenous fistulas. J Neurosurg 2017;126:1884-93 CrossRef Medline

23. Gailloud P, Oishi S, Carpenter J, et al. Three-dimensional digital angiography: new tool for simultaneous three-dimensional rendering of vascular and osseous information during rotational angiography. AJNR Am J Neuroradiol 2004;25:571-73 Medline

24. Kiyosue H, Tanoue S, Okahara M, et al. Angioarchitecture of transverse-sigmoid sinus dural arteriovenous fistulas: evaluation of shunted pouches by multiplanar reformatted images of rotational angiography. AJNR Am J Neuroradiol 2013;34:1612-20 CrossRef Medline

25. Lasjaunias $\mathrm{P}$, Berenstein A, terBrugge K. Clinical and endovascular treatment aspects in adults. In: Surgical Neuroangiography. Vol 2. 2nd ed. Heidleberg: Springer-Verlag; 2004

26. Baltsavias G, Spiessberger A, Hothorn T, et al. Cranial dural arteriovenous shunts, Part 4: clinical presentation of the shunts with leptomeningeal venous drainage. Neurosurg Rev 2015;38:283-91; discussion 291 CrossRef Medline

27. Signorelli F, Gory B, Maduri R, et al. Intracranial dural arteriovenous fistulas: a review of their current management based on emerging knowledge. J Neurosurg Sci 2017;61:193-206 CrossRef Medline

28. Koyanagi M, Kobayashi T, Oda M, et al. Dural arteriovenous fistula in the falx cerebri treated with transarterial embolization using $\mathbf{n}$ butyl cyanoacrylate. Surg Neurol Int 2016;7:S1057-59 CrossRef Medline

29. Velat GJ, Reavey-Cantwell JF, Sistrom C, et al. Comparison of Nbutyl cyanoacrylate and Onyx for the embolization of intracranial arteriovenous malformations: analysis of fluoroscopy and procedure times. Neurosurgery 2008;63:ONS73-78; discussion ONS78-80 CrossRef Medline

30. Chen J, Crane B, Niparko J, et al. Direct intraoperative confirmation of penetration of ethylene vinyl alcohol copolymer (Onyx) into the vasa nervosa of the facial nerve. J Neurointerv Surg 2012;4:435-47 CrossRef Medline

31. Chapot R, Stracke P, Velasco A, et al. The pressure cooker technique for the treatment of brain AVMs. J Neuroradiol 2014;41:87-91 CrossRef Medline

32. Abecassis IJ, Nerva JD, Ghodke BV, et al. The dual microcatheter technique for transvenous embolization of dural arteriovenous fistulae. J Neurointerv Surg 2017;9:578-82 CrossRef Medline

33. Zhang G, Zhu S, Wu P, et al. The transvenous pressure cooker technique: a treatment for brain arteriovenous malformations. Interv Neuroradiol 2017;23:194-99 CrossRef Medline

34. Ye M, Zhang P. Transvenous balloon-assisted Onyx embolization of dural arteriovenous fistulas of hypoglossal canal. Neuroradiology 2018;60:971-78 CrossRef Medline

35. Colby GP, Coon AL, Huang J, et al. Historical perspective of treatments of cranial arteriovenous malformations and dural arteriovenous fistulas. Neurosurg Clin N Am 2012;23:15-25 CrossRef Medline 